\title{
Pengembangan Media Bantu Latihan Bertahan Pada Bola Voli Tahun 2019
}

\section{Media Development Helps Defensive Training in Volleyball in 2019}

\author{
Ramlan Sahputera Sagala", Dicky Edwar Daulay \\ Program Studi Pendidikan Jasmani Kesehatan Dan Rekreasi, Universitas Pembinaan Masyarakat \\ Indonesia, Jalan Teladan No. 15, Medan Kota, 20214, Sumatera Utara, Indonesia \\ e-mail: ramlansahputerasagala@gmail.com, dickyedwar89@gmail.com
}

\begin{abstract}
Abstrak
Penelitian ini adalah bertujuan untuk mengembangkan media bantu latihan bertahan dalam permainan bola voli tahun 2019. Populasi dalam penelitian ini adalah 10 orang atlet bola voli PBV. Pem. Panjang, 10 orang atlet PBV. Sukaraja dan 10 orang atlet PBV. 50 tahun 2019. Hasil uji kelompok kecil melibatkan 20 orang atlet, 10 orang atlet bola voli PBV Pem. Panjang dan 10 orang atlet PBV 50 menunjukkan bahwa pengembangan media batu latihan bertahan dalam permainan bola voli tahun 2019 dapat disimpulkan bahwa media bantu latiam bertahan ini memenuhi kriteria untuk dilanjutkan dalam uji coba kelompok besar dengan syarat setelah perbaikan karena persentase dari peryataan angket antara 45\%-74\%. Hasil uji kelompok besar melibatkan 30 atlet, 10 orang atlet bola voli PBV Pem.Panjang, 10 orang atlet PBV 50 dan 10 orang atlet PBV Sukaraja bahwa pengembangan media bantu latihan bertahan dalam permainan bolavoli tahun 2019 dapat disimpulkan bahwa media bantu latihan bertahan memenuhi kriteria untuk digunakan dalam membantu latihan bertahan atlet karena persentase dari peryataan angket antara 78\%-85\%. Sehingga dapat disimpulkan bahwa media bantu latihan bertahan ini dapat digunakan untuk melatih bertahan.
\end{abstract}

Kata Kunci : Bertahan, Latihan, bola voli

\begin{abstract}
This study aims to develop defense training aids in volleyball 2019. The population in this study was 10 PBV volleyball athletes. Pem.Panjang, 10 PBV athletes. Sukaraja and 10 PBV athletes. 50 in 2019. The results of small group tests involving 20 athletes, 10 PBV Pem.Panjang volleyball athletes and 10 PBV 50 athletes showed that the development of defense stone training tools in volleyball 2019 can be concluded that these defense latiam aids meet the criteria to be continued in trials large groups with conditions after repairs due to the percentage of questionnaire statements between $45 \%-74 \%$. The results of a large group test involving 30 athletes, 10 PBV Pem.Panjang volleyball athletes, 10 PBV 50 athletes and 10 PBV Sukaraja athletes that the development of defense training aids in the 2019 volleyball game can be concluded that defense training aids meet the criteria for use in helps athlete defense training because the percentage of questionnaire statements is between $78 \%-85 \%$. So it can be concluded that this defense training aid can be used to train defense.
\end{abstract}

Keywords : Defense, Training, volleyball

corresponding author: ramlansahputerasagala@gmail.com

Artikel Info:

Submitted: 23/10/2020

Revised : 27/10/2020

Accepted : 01/11/2020

Published: 16/11/2020

(c) (i)

Journal Coaching Education Sports is licensed under a Creatives Commons Attribution 4.0 International License. 


\section{A. Pendahuluan}

Ada banyak jenis dan macam olahraga yang ada di dunia ini, baik itu olahraga yang bersifat individu maupun olahraga yang bersifat team (Widodo, 2018). Jadi, tidak heran jika olahraga begitu banyak di minati dan di gemari di dunia terkhususnya di Indonesia. Sebab dengan berolahraga dapat membuat tubuh kita lebih segar, lebih sehat dan bugar secara jasmani (Hanief et al., 2018). Selain itu, olahraga juga dapat di kategorikan menjadi olahraga rekreasi dan olahraga prestasi. Jadi, upaya yang dapat di lakukan meningkatkan prestasi dalam berolahraga, tentunya dibutuhkan pembinaan di mulai dari usia dini, tentunya dengan memberikan pelatihan baik itu teknik, taktik, mental, dan strategi (Pasaribu, 2016).

Dari berbagai macam dan jenis olahraga yang ada di dunia, salah satu olahraga yang sangat di gemari adalah bola voli. Tidak hanya di dunia, di Indonesia olahraga bola voli juga sangat di gemari oleh masyarakat Indonesia. Tidak hanya masyarakat kota yang menggemari bola voli di Indonesia, namun juga di gemari oleh masyarakat pedesaan. Oleh karena itu olahraga bola voli banyak di pertandingkan, mulai dari tingkat desa, kabupaten, nasional hingga internasional.

Maka dari itu, untuk mendapatkan hasil yang maksimal dan memuaskan dalam permainan bola voli seorang atlet di tuntut untuk menguasai teknik dasar dalam permainan bola voli (Hamzah et al., 2019). Sebab, dalam permainan bola voli menguasai teknik dasar merupakan hal yang penting untuk mendapatkan hasil yang memuaskan (Juniarta et al., 2017). Adapun teknik dasar yang harus di kuasai tersebut adalah passing atas, passing bawah, smash, block, dan service yang meliputi service bawah, service atas, dan service lompat (jumping service) (Oktariana \& Hardiyono, 2020).

Dalam hal ini, permainan bola voli juga memerlukan pertahanan yang baik yaitu bertahan. Bertahan ialah bagian dari passing bawah (Pasaribu, 2016). Bertahan merupakan suatu gerakan menerima serangan lawan denganmenggunakan satu tangan atau dua tangan (Sahabuddin et al., 2020). Bertahan merupakan kemampuan untuk menahan dan mengimbangi smashsmash pihak lawan (Candra et al., 2019).

Dari ungkapan di atas dapat disimpulkan bahwa keterampilan bertahan merupakan suatu teknik pertahanan yang utama dan cukup penting. (Prasetio et al., 2014) menyatakan bahwa bertahan merupakan teknik bertahan untuk menerima dan mengimbangi serangan lawan dengan menggunakan satu atau dua tangan agar 
dapat melakukan serangan balik kepada tim lawan untuk memperoleh atau menghasilkan poin. Jadi, semakin baik bertahan yang di lakukan sebuah tim, maka semakin besar pula kemungkinan sebuah tim untuk memperoleh atau menghasilkan poin.

Berdasarkan permasalahan dan hasil yang dikemukan diatas, akan dapat memperkuat peneliti bahwa di perlukannya media bantu dalam latihan bertahan bola voli, yang di harapkan dapat meningkatkan kemampuan bertahan para atlet dan dapat membantu pelatih dalam latihan (Wa'asil et al., 2019). Oleh karena itu, peneliti tertarik untuk mengadakan penelitian dengan judul : "Pengembangan Media Bantu Latihan Bertahan Pada Permainan Bola Voli Tahun 2019".

Permainan bola voli merupakan salah satu cabang olahraga berbentuk memvoli bola di udara bolak-balik di atas jaring/net, dengan maksud menjatuhkan bola dalam petak lapangan lawan untuk mencari kemenangan (Fallo \& Hendri, 2016). Memantulkan bola ke udara dapat menggunakan bagian tubuh mana saja, asalkan perkenaannya harus sempurna (Rohadi, 2018). Permainan bola voli dimainkan oleh dua regu yang masingmasing regu terdiri dari enam orang pemain (Hanief et al., 2018).

Permainan bola voli adalah suatu cabang olahraga yang dimainkan oleh dua regu, dimana masing- masing terdiri dari 6 orang pemain dengan tujuan memvoli bola dan menjatuhkan bola ke daerah lapangan lawan untuk mendaoatkan poin (Pasaribu, 2016). Permainan bolavoli ini menggunakan sistem reli point dengan game setiap setnya 25 poin, dan tim yang mendapatkan 3 set terlebih dahulu maka tim tersebut dinyatakan sebagai pemenang (Candra et al., 2019). Apabila terjadi poin 24 sama (duace) makan di teruskan dengan mencari selisih 2 poin, dan apabila terjadi raber set atau kedudukan skor 2-2 maka di lanjutkan dengan satu set penetuan dengan game 15 poin (Juniarta et al., 2017).

Permainan bola voli diharuskan menguasai beberapa teknik-teknik tertentu. Teknik erat sekali hubungannya dengan kemampuan gerak, kondisi fisik, taktik, dan mental (Faozi et al., 2019). Teknik dasar bola voli harus betul-betul dipelajari terlebih dahulu guna dapat mengembangkan mutu prestasi permainan bola voli. Penguasaan teknik dasar permainan bola voli merupakan salah satu unsur yang ikut menentukan menang atau kalahnya suatu regu dalam pertandingan disamping unsur-unsur kondisi fisik, taktik, dan mental (Gotama et al., 2016).

Teknik dasar bola voli adalah prosedur 
gerakan yang digunakan dalam setiap permainan bola voli dimana gerakan-gerakan dilakukan bertujuan untuk mencapai hasil yang maksimal (Suardi, 2019).

Bertahan ialah bagian dari passing bawah. Bertahan merupakan suatu gerakan menerima serangan lawan dengan menggunakan satu tangan atau dua tangan (Mundiri \& Widodo, 2019). Bertahan merupakan kemampuan untuk menahan dan mengimbangi smash-smash pihak lawan (Wa'asil et al., 2019). Seorang pemain dapat digolongkan sebagai defender yang baik kalau ia berani terjun dalam perainan dengan penuh keberanian dan ketabahan, sudah memperkembangkan kemempuannya untuk menahan dan mengimbangi smash-smash pihak lawan (Muttaqin, 2016).

Keterampilan bertahan merupakan suatu teknik pertahanan yang utama dan cukup penting. Secara umum bertahan merupakan teknik bertahan dari serangan lawan dan bersiap untuk melakkan serangan balik kepada lawan (Suardi, 2019). Bertahan merupakan teknik untuk menerima dan mengimbangi serangan lawan dengan menggunakan satu atau dua tangan agar dapat melakukan serangan balik kepada tim lawan untuk memperoleh atau menghasilkan poin (Prasetio et al., 2014). Jadi, semakin baik bertahan yang di lakukan sebuah tim, maka semakin besar pula kemungkinan sebuah tim untuk memperoleh atau menghasilkan poin.

Menurut (Kusumawati, 2017) mengatakan bahwa "latihan adalah suatu proses atau dinyatakan dengan kata lain, periode waktu yang berlangsung selama beberapa tahun, sampai olahragawan atau olahraga waji tersebut mencapai standard penampilan yang tinggi. (Pujianto et al., 2020) Latihan dasar untuk pemula biasanya berlangsung selama dua tahun, tahap selanjutnya dua tahap lagi dan latihan lanjutan kira-kira dua sampai empat tahun, naik sampai kemampuan maksimal”.

Proses latihan selalu bertujuan untuk meningkatkan kualitaas fisik olahragawan, dimana kualitas fisik meliputi kondisi fisiologis (Budiman, 2013). Akibatnya jika terjadi kesalahan dalam menentukan komponen latihan dapat menyebabkan tujuan latihan tidak dapat tercapai atau proses latihan tidak memberikan dampak yang positif, sehingga tidak akan terjadi proses seperkompensasi (hiperkompensasi) . Imran Akhmad (2013:6). Menurut Kamus Besar Bahasa Indonesia pengertian media yaitu:

1. Benda yang dipakai untuk mengerjakan sesuatu: perkakas; perabot(an);

2. Yang dipakai untuk mencapai maksud; 
3. Perlengkapan

Media bantu menurut (Aminudin, 2018) adalah media yang digunakan pengajar dalam menyampaikan materi, dengan adanya media peraga maka bahan ajar atau materi akan lebih mudah dimengerti oleh peserta didik.

Menurut (Komalasari, 2020), penekanan media bantu belajar terhadap pada visual dan audio. Media bantu visual terdiri dari media peraga dua dimensi hanya menggunakan dua ukuran panjang dan lebar (seperti : gambar, bagan, dan grafik), sedangkan media peraga tiga dimensi menggunakan tiga ukuran yaitu panjang, lebar, dan tinggi (seperti benda asli, media tiruan sederhana, dan barang contoh).

Media merupakan suatu benda yang digunakan untuk membantu dan meringankan suatu kegiatan. Maka dengan adanyanya media ini dapat membantu proses latihan lebih menarik dan efektif (Priyanto \& Ulinnuha, 2017).

Setelah mengumpulkan informasi dari masalah-masalah yang ada dilapangan, peneliti merancang desain yang sesuai dengan masalah tersebut, peneliti juga melakukan analisis materi. Dari hasil analisis yang di lakukan peneliti dapat dijadikan acuan dalam meciptakan produk. Kebutuhan dalam mendesain produk ini disesuaikan dengan keefektifan dan keefisianan. Produk penelitian ini akan menciptakan sebuah media bantu latihan bertahan yang sudah dimodifikasi dari media sebelumnya yang berupa media minitrampoline.

Tahap selanjutnya dalam penelitian ini adalah desain produk. Dalam hal ini desain produk adalah pembuatan media yang berupa rancangan media bantu latihan bertahan bola voli yang berupa rangka dan menyusunnya. Semua rangka dan kebutuhan yang dibutuhkan sudah di rancang dengan maksimal. Adapun rancangan desain produk media bantu latihan bertahan adalah sebagai berikut :

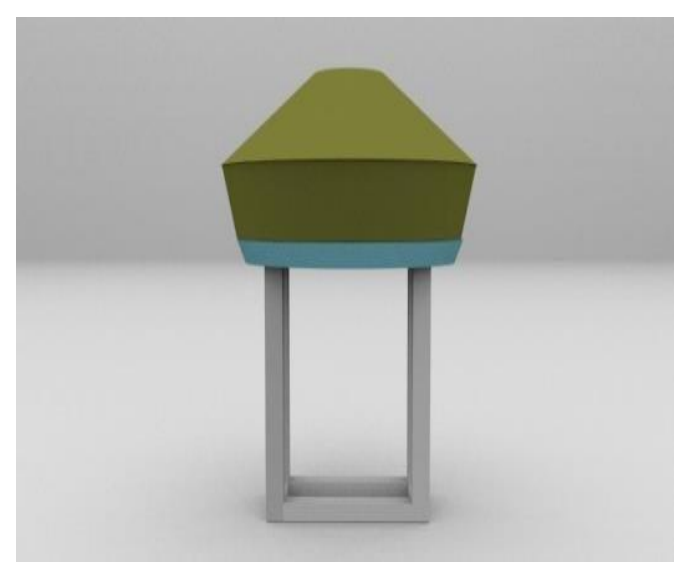

\section{B. Metode Penelitian}

Sasaran penelitian atau pengguna yang menjadi sasaran dalam penelitian pengembangan media bantu latihan bertahan pada bola voli adalah seluruh atlet bola voli. Untuk para pelatih dan pembina cabang 
olahraga bola voli untuk menjadikan media bantu latihan bertahan pada bola voli ini dapat membantu pelatih dalam latihan dengan harapan dapat meningkatkan kemampuan bertahan atletnya dan mempertinggi prestasi atletnya.

Tempat penelitian dilaksanakan di tempat latihan club Pem.Panjang vc, Sukaraja vc, dan PBV 50. Penelitian ini dilaksanakan pada tanggal 22, 24 Juli 2019 dan 1,10,23 Oktober 2019. Penyusunan sampel uji coba pada penelitian ini dengan tahap uji tahap I (kelompok kecil 2 club) dan uji tahap II (kelompok besar 3 club) ditujukan pada atlet:

a. Pada uji coba tahap I (kelompok kecil) disarankan dapat melibatkan subyek sebanyak- banyaknya 20 orang, sekurang- kurangnya 8 orang. Dalam penelitian ini peneliti melibatkan pada uji coba kelompok kecil berjumlah 10-15 atlet, dari atlet Club Bola Voli Pem.Panjang vc dan Club Bola voli PBV Sukaraja.

b. Pada uji coba tahap II (kelompok besar) dalam penelitian ini peneliti melibatkan sebanyak 15- 30 atlet yang masih aktif berlatih di klub Pem.Panjang vc, PBV Sukaraja dan PBV 50.

Metode yang digunakan pada penilitian ini adalah penelitian pengembangan Research and development (R\&D) yang mencakup : mengembangkan produk, menguji keefektifan produk untuk mencapai tujuan yang diinginkan (Arikunto, 2019). Hasil akhir dari kegiatan penilitian dan pengembangan ini adalah media bantu latihan bertahan dalam permainan bola voli yang baru dan dilengkapi dengan spesifkasi produknya, sehingga dapat digunakan dalam latihan bola voli dan menjadikan latihan lebih menarik dan bervariasi.

Implementasi merupakan suatu tindakan atau pelaksanaan dari sebuah rencana matang dan terperinci. Peneliti mengimplementasikan dan menyebarkan produk (Desiminasi) yang sudah mengalami revisi dan sudah final kepada para pengguna seperti pembina olahraga melalui buku dan vidio tentang mediabantu katihan bertahan dalam permainan bola voli yang baru dan menuliskan dalam jurnal. Sebagai evaluasi sumatif maka produk akan didesiminasi pada klub-klub bola voli. Sehingga peneliti dapat melihat keefektifan dan keefesienan produk dalam proses latihan.

Pada penelitian pengembangan ini teknik analisa data yang digunakan adalah teknik analisis deskriptif kuantitatif dengan persentase. Teknik ini digunakan agar mendapat analisa data kuantitatif yang 
didapatkan dari penyebaran angket.

Adapun produk dari penelitian yang merupakan pengembangan media bantu latihan bertahan dalam permainan bola voli adalah latihan bertahan dengan menggunakan media media trampoline mini yang sudah dimodifikasi dengan pendekatan bermain dan drill.

Hasil penelitian ini dapat digunakan menjadi bahan acuan dan masukan kepada pelatih dalam memvariasikan latihan denagan menggunakan media bantu dalam permainan bola voli, khususnya latihan bertahan dalam permainan bola voli.

\section{Hasil dan Pembahasan}

Dari hasil observasi yang dilakukan peneliti dengan cara mengamati, melihat serta wawancara, maka peneliti melakukan analisis kebutuhan kepada 30 orang atlet bola voli. Sehingga diperoleh $100 \%$ senang dengan olahraga bola voli, $67 \%$ dapat melakukan bertahan dengan baik, 70\% pernah melakukan latihan bertahan dengan menggunakan media bantu,73\% mengetahui adanya media bantu latihan bertahan, 93\% ingin menggunakan media bantu latihan bertahan yang baru ,93\% membutuhkan media bantu dalam 1 atihan bertahan, 93\% diperlukan media bantu latihan bertahan bola voli yang baru.
Dari analisis kebutuhan di atas, dapat di simpulkan bahwa seluruh atlet bola voli dan pelatih membutuhkan media bantu latihan bertahan dalam latihanbola voli dengan harapan dapat meningkatkan kemampuan bertahan atlet dan dapat meningkat prestasi atlet dalam permainan bola voli. Dengan media bantu latihan bertahan ini dapat membantu pelatih dalam membuat program latihan yang lebih bervariasi saat menggunakan latihan bertahan dengan tujuan untuk membuat atlet lebih berprestasi.

Pengembangan produk ini bertujuan untuk meningkatkan kemampuan atlet saat melakukan bertahan dalam permainn bola voli. Media ini sangat membantu pelatih dalam latihan untuk meningkatkan kemampuan bertahan para atlet terutama dalam melakukan bertahan dalam permainan bola voli. Media latihan dengan menggunakan media bantu latihan bertahan ini dapat digunakan baik untuk atlet junior maupun senior dalam melakukan latihan bertahan karena kegunaan media ini sangat membantu pelatih dalam meningkatkan kemampuan bertahan para atlet dengan ukuran dan tinggi yang sudah di sesuaikan dan dengan cara penggunaannya.

Berdasarkan pembahasan pengembangan media bantu latihan bertahan dalam 
permainan bola voli tersebut memiliki keunggulan :

1. Atlet lebih termotivasi dalam melakukan latihan karena adanya variasi ketika melakukan latihan bertahan.

2. Atlet lebih bersemangat dalam latihan dengan adanya media bantu latihan bertahan tersebut.

3. Atlet mendapatkan pengalaman baru dalam latihan ketika letihan menggunakan media bantu bertahan.

4. Dapat membantu pelatih dalam melatih bertahandengan dengan adanya media bantu Latihan bertahan dan varisi-varasi dalam peng-gunaannya.

Berdasarkan beberapa keunggulan tersebut, media ini juga memiliki beberapa kekurangan seperti sedikit sulit dalam megunakannya dalam mendapatkan filling ketika me- mantulkan bola.

Kualitas "Pengembangan Media Bantu Latihan Bertahan Pada Permainan Bola voli Tahun 2019" ini termasuk kriteria dapat "Digunakan", pernyataan tersebut disimpulkan dari hasil analisis penilaian tiga ahli mendapatkan $67 \%$ dari rata-rata pengisian semua angket pada validsi desain dan mendapatkan $83 \%$ dari rata-rata pengisian semua angket pada validasi uji coba produk, uji coba kelompok kecil 20 subjek dengan 7 pertanyaan mendapatkan 45\%-74\% dan uji coba kelompok besar 30 subjek dengan 7 pertanyaan mendapatkan $78 \%-85 \%$.

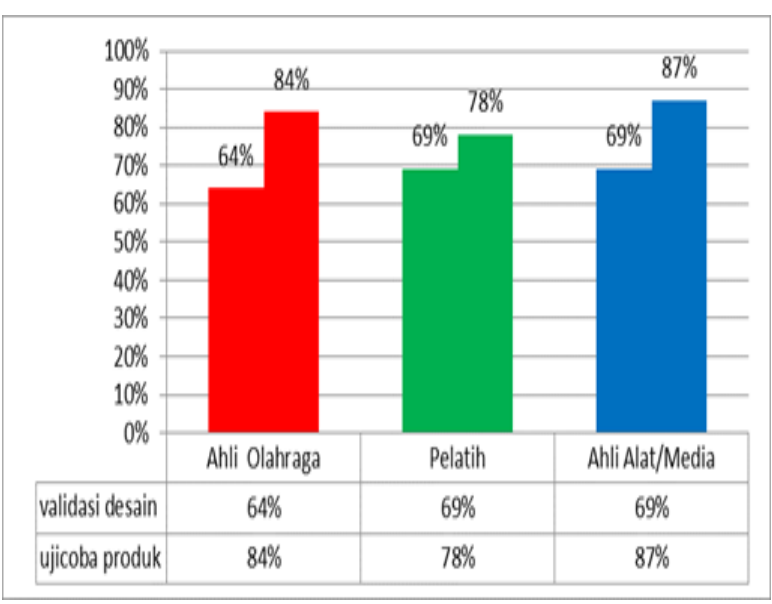

Gambar 2. Perbandingan Hasil Evaluasi Ahli

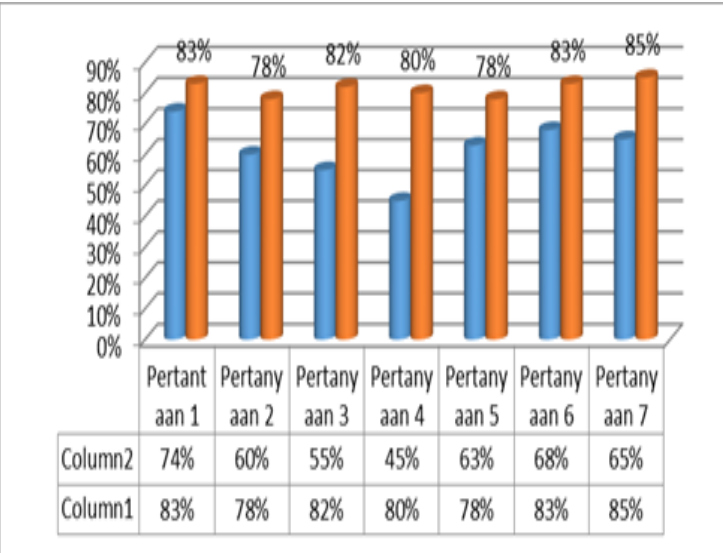

Gambar 3. Perbandingan hasil Uji

Pemakaian Atlet

\section{Kesimpulan}

Berdasarkan hasil uji coba lapangan dan hasil pmbahasan peneliti, sehingga dapat 
disimpulkan bahwa : Diperlukan media bantu latihan bertahan dalam permainan bola voli. Dengan adanya media bantu bertahan yang dikembangkan. dapat meningkat kemampuan bertahan atlet dalam permaian bola voli. Dengan adanya media bantu latihan bertahan yang dikembangkan, atlet lebih termotivasi dan lebih semangat dalam latihan. Dengan adanya media bantu latihan bertahan yang dikembangkan, latihan bertahan lebih bervariasi dengan menggunakan media bantu latihan bertahan. Dengan adanya media ini dapat membantu pelatih dalam melakukan latihan bertahan.

Pelatih dapat melakukan variasi dalam melakukan latihan bertahan untuk meningkatkan kemampuan bertahan para atlet yang dilatih.

\section{Daftar pustaka}

Aminudin, R. (2018). Upaya meningkatkan hasil belajar tendangan sabit pada cabang olahraga pencak silat melalui media bantu statis pada siswa kelas viii smpn 1 jatisari. Jurnal Speed (Sport, Physical Education, Empowerment), 1(1), 58-64. https://doi.org/https://doi.org/10.35706/ speed.v1i1.1499

Arikunto, S. (2019). Prosedur Penelitian Suatu Pendekatan Praktik. Rineka
Cipta.

Budiman, W. (2013). Pengaruh Model Pembelajaran Kooperatif Tipe Jigsaw Dan Motivasi Belajar Terhadap Prestasi Belajar Ilmu Fisiologi Olahraga. Jurnal Pendidikan Indonesia, 2(1), 138-144. https://doi.org/10.3102/0013189X1878 5613

Candra, J., Pasaribu, A. M. N., \& Fauzan, A. (2019). Pembuatan Mesin Pelontar Bola (Penbal) Alat Bantu Pembelajaran Dan Latihan Olahraga Bolavoli. Jurnal Prestasi, 3(6), 73. https://doi.org/10.24114/jp.v3i6.15899

Fallo, I. S., \& Hendri, H. (2016). Upaya Meningkatkan Keterampilan Smash

Permainan Bola Voli Melalui Pembelajaran Gaya Komando. Jurnal Pendidikan Olahraga, 5(1), 10-19. https://doi.org/http://dx.doi.org/10.3157 1/jpo.v5i1.309

Faozi, F., Sanusi, H., \& Listiandi, A. D. (2019). Pengaruh Model Pembelajaran Kooperatif Tipe Stad Terhadap Keterampilan Passing Bawah Dalam Permainan Bola Voli Di SMA Islam AlFardiyatussa'adah Citepus

Palabuhanratu. Physical Activity Journal, $\quad 1(1), \quad 51$. https://doi.org/10.20884/1.paju.2019.1. 1.2001 
Gotama, M. R., Adi, I. P. P., Luh, N., \& Spyanawati, P. (2016). Untuk Meningkatkan Aktivitas Dan Hasil Belajar Passing Bola Voli. Jurnal Pendidikan Jasmani, Olahraga Dan Kesehatan Undiksha, 1(2), 1-13. https://ejournal.undiksha.ac.id/index.ph p/JJP/article/view/6902

Hamzah, I., Ginanjar, A., \& Setiawan, A. (2019). Pengaruh Model Pembelajaran Jigsaw Terhadap Hasil Belajar Passing Bawah Bola Voli. Jurnal Kependidikan Jasmani Dan Olahraga, 3(1), 58-63. https://ejournal.stkipnu.ac.id/public_ht ml/ejournal/index.php/jkjo/article/view/ 58

Hanief, Y. N., Mashuri, H., \& Subekti, T. B. A. (2018). Menignkatkan Hasil Belajar Passing Bawah Bola Voli Melalui Permainan 3 on 3 pada Siswa Sekolah Dasar. Jurnal Pendidikan Jasmani Dan Olahraga, 3(76), 161-166. https://doi.org/https://doi.org/10.17509/ jpjo.v3i2.12414

Juniarta, I. P., Kanca, I. N., \& Putra, A. (2017). Penerapan Model Pembelajaran Kooperatif STAD Meningkatkan Aktivitas dan Hasil Belajar Teknik Dasar Passing Bolavoli. Jurnal Pendidikan Jasmanai Kesehatan Dan Rekreasi, $\quad 7(2), \quad 1-11$. https://ejournal.undiksha.ac.id/index.ph p/JJP/article/view/11346

Komalasari. (2020). Upaya Meningkatkan Penguasaan Senam Ketangkasan Melalui Pendekatan Bermain dan Media Bantu dalam Pembelajaran Penjasorkes bagi Siswa SD Negeri 44 Ampenan. Jurnal Teknologi Pendidikan (JTP), $5(2)$, 159-166.

https://doi.org/10.24114/jtp.v8i2.3329

Kusumawati, O. (2017). Pengaruh Permainan Tradisional Terhadap Peningkatan Kemampuan Gerak Dasar Siswa Sekolah Dasar Kelas Bawah. Jurnal Pendidikan Dan Pembelajaran Dasar, 4 , 124-142. https://doi.org/https://doi.org/10.24042/ terampil.v4i2.2221

Mundiri, M. T. Al, \& Widodo, A. (2019). Pengembangan Model Latihan Bertahan Berbasis Analisi Video Pertandingan Juventus FC VS Tottenham Hotspur FC dalam Pertandingan 16 Besar Liga Champions 2018. Jurnal Kesehatan Olahraga, $\quad 7(2), \quad$ 129-134. https://jurnalmahasiswa.unesa.ac.id/ind ex.php/jurnal-kesehatanolahraga/article/view/27754/25398 Muttaqin, I. (2016). Pengembangan Model Latihan Smash Bolavoli Pada Kegiatan Ekstrakurikuler Di SMPN 12 Malang. 
Jurnal Pendidikan Jasmani, 26(2), 257272.

https://doi.org/http://dx.doi.org/10.1797

7/pj.v26i2.7505

Oktariana, D., \& Hardiyono, B. (2020). Pengaruh Daya Ledak Otot Lengan, Daya Ledak Otot Tungkai Dan Kekuatan Otot Perut Terhadap Hasil Smash Bola Voli Pada Siswa SMK Negeri 3 Palembang. Journal Coaching Education Sports, 1(1), 13-24. https://doi.org/10.31599/jces.v1i1.82

Pasaribu, A. M. N. (2016). Pengaruh Gaya Menagajar dan Motivasi Belajar Passing Bawah dalam Permainan Bola Voli pada Siswa SMP Kelas VIII. Jurnal SPORTIF: Jurnal Penelitian Pembelajaran, 2(2), 85-97. https://doi.org/https://doi.org/10.29407/ js_unpgri.v2i2.510

Prasetio, E. F., Dwiyogo, W. D., \& Sudjana, I. N. (2014). Pengembangan Multimedia Interaktif Model Latihan Bertahan ( Defense ) Sepakbola Pada Ekstrakurikuler Sepakbola Di Smp Negeri 15. Pendidikan Jasmani, 26(1), 129-144.

https://doi.org/http://dx.doi.org/10.1797

7/pj.v26i1.7735

Priyanto, A., \& Ulinnuha, F. (2017).

Perancangan Aplikasi Penerjemah
Bahasa Indonesia Ke Bahasa Jawa Untuk Media Bantu Belajar Siswa SMK Salafiyah Berbasis Android. Indonesian Journal of Network \& Security, 6(4), 39-46.

https://doi.org/http://dx.doi.org/10.2311 /ijns.v6i4.1473

Pujianto, D., Sutisyana, A., Arwin, A., \& Nopiyanto, Y. E. (2020). Pengembangan Model Latihan Passing Sepakbola Berbasis Sasaran Teman. Journal Coaching Education Sports, l(1), $1-12$. https://doi.org/10.31599/jces.v1i1.81

Rohadi, A. (2018). Metode Latihan Pembelajaran Bola Voli Untuk Umum (2nd ed.). Alfabeta.

Sahabuddin, Hakim, H., \& Syahruddin. (2020). Meningkatkan Keterampilan Proses Passing Bawah Bolavoli Melalui Pembelajaran Kooperatif. Jurnal Penjaskesrek, 7(1), 15-27. https://doi.org/https://doi.org/10.46244/ penjaskesrek.v7i2.1050

Suardi, D. (2019). Analisis Kebutuhan Keterampilan Bertahan Dalam Permainan Bolavoli. Cakrawala Pedagogik, $\quad 3(2), \quad$ 93-99. https://doi.org/10.51499/cp.v3i2.106 Wa'asil, F., Hernawan, H., \& Humaid, H. (2019). Defense Exercise Model of 
Volleyball Fw for Beginner. Jurnal

Pendidikan Olahraga, 7(2), 96. https://doi.org/10.31571/jpo.v7i2.1166

Widodo, A. (2018). Makna Dan Peran Pendidikan Jasmani Dalam Pembentukan Insan. Jurnal Motion, 9(1), 53-60. https://www.researchgate.net/publicatio n/329442726_MAKNA_DAN_PERAN _PENDIDIKAN_JASMANI_DALAM _PEMBENTUKAN_INSAN_YANG_ MELEK_JASMANIAHTERLITERASI_JASMANIAHNYA 